\title{
POLITICAS DE JUVENTUD Y EMPLEO JUVENIL: EL TRAJE NUEVO DEL REY*
}

Miguel ABAD**

\begin{abstract}
RESUMEN
De forma similar a las representaciones idealistas de la condición juvenil, los análisis predominantes sobre el desempleo juvenil y sus alternativas de paliación consideran el fenómeno de manera aislada y descriptiva, sin reparar en las contradicciones capitalistas y su influencia sobre las relaciones institucionales y político/jurídicas que rigen las nuevas formas de organización y división internacional del trabajo. Sin embargo, es el contexto del desempleo juvenil, y no el desempleo en sí mismo, el que debe ser articulado a la totalidad del mundo laboral, con sus múltiples relaciones y contradicciones, y la manera como es afectado por la reestructuración del capitalismo a escala mundial. Para hacer explícitas estas cuestiones y revelar su dinámica, es necesario situar las políticas de empleo juvenil en América Latina en el marco de la transición mundial de un capitalismo bajo la hegemonía fordista en la organización social del trabajo, con su respectiva forma-estado, a un capitalismo postfordista y su forma-estado correspondiente, momentos diferenciados por condiciones de acumulación de capital y mecanismos específicos de regulación del antagonismo de clases.

Palabras Clave: Desempleo, CAPITAlismo, Condición JUVENIL

* Conferencia presentada en el Observatorio de Juventud de la Universidad Estadual Fluminense, Río de Janeiro, diciembre 2004.

** Psicólogo argentino y consultor internacional en políticas públicas de juventud, autor de varios artículos y libros en el tema. Brasil.

E-Mail: miguelabad2000@yahoo.com.ar.
\end{abstract}




\title{
POLITICAS DE JUVENTUDE E EMPREGO JUVENIL: A ROUPA NOVA DO REI
}

\begin{abstract}
RESUMO
De forma semelhante às representações idealistas da condição juvenil, as análises predominantes sobre o desemprego juvenil e suas alternativas suavisantes consideram o fenômeno de forma isolada e descritiva, sem reparar nas contradições capitalistas e sua influência sobre as relações institucionais e político-jurídicas que regem as novas formas de organização e divisão internacional do trabajo. Entretanto, é o contexto do desemprego juvenil, e não o desemprego em si mesmo, o que deve ser articulado à totalidade do mundo do trabalho, com suas múltiplas relações e contradições, e a maneira como é afetado pela reestruturação do capitalismo em escala mundial. Para fazer explícitas estas questões e revelar sua dinâmica, é necessário situar as políticas de emprego juvenil na América Latina no marco da transição mundial de um capitalismo sob a hegemonia fordista na organização social do trabalho, com sua respectiva forma-estado, a um capitalismo pós-fordista e sua forma-estado correspondente, momentos diferenciados por condições de acumulação de capital e mecanismos específicos de regulamentação do antagonismo de classes.
\end{abstract}

Palavras chave: Desemprego, CaPitalismo, Condição JUVEnIL

YOUTH POLITICS AND JUVENILE EMPLOYMENT: THE KING'S NEW SUIT

\begin{abstract}
Similar to the idealistic representations of the youth condition, the predominant analysis on youth unemployment and the way in which it can be solved, considerates the phenomenon of isolation in a descriptive way, without repairing capitalistic contradictions and its influence on the institutional and political-judicial relations that govern the new forms of organizations and international divisions of work. Nevertheless, it is the context of labor unemployment, with its multiple relations and contradictions, and the way as it is affected by the reconstruction of capitalism on a world-wide scale. In order to make it these questions evident and to reveal its dynamics, it is necessary to put the politics of juvenile work within the the frame of the world transtition of Capitalism in Latin America under the fordistic supremacy in the social organization of work, with its respective state of being, corresponding to its post-fordistic capitalism and its state form, momentarily differentiated by conditions of the accumulation of capital and specific mechanisms of the regulation of antagonism of classes.
\end{abstract}

KEY WORDS: UNEMPLOYMENT, CAPITALISM, THE YOUTH CONDITION 
Me gustaría ser sabio también/Los viejos libros explican la sabiduria:/ Apartarse de las luchas del mundo/Y transcurrir sin inquietudes nuestro breve tiempo/Librarse de la violencia,/ Dar bien por mal,/ No satisfacer los deseos y hasta olvidarlos: tal es la sabiduría/ Pero yo no puedo hacer nada de esto,/ Verdaderamente vivo en tiempos sombríos. BERTOLT BRECHT

\section{Presentación}

EL «PROBLEMA DEL DESEMPLEO juvenil» en las periferias latinoamericana, que asume características propias, también se presenta con idéntica insidia en los países centrales. Sin embargo, el hecho de darse además en América Latina, los ha convertido, para el discurso dominante en las políticas públicas que abordan la temática, en un problema del desarrollo capitalista latinoamericano, cuya precariedad es causa del fenómeno de la exclusión sociolaboral de la juventud.

Este ensayo, que no pretende ser más que unas reflexiones todavía preliminares que requieren profundizarse y sumar evidencia empírica, quiere abrir una polémica sosteniendo la tesis contraria: antes que consecuencia de la débil implementación de las estructuras institucionales y jurídicas del capitalismo y sus subsiguientes deficiencias, cuya solución sería mejorar las condiciones que permitan su pleno desenvolvimiento, lo que explica la situación del empleo juvenil en nuestros países no es una «anomalía» del desarrollo latinoamericano, sino ese mismo desarrollo, el único corolario económico posible en la periferia del sistema capitalista mundial, bajo las leyes que gobiernan las formaciones socioeconómicas de su fase terminal-mundial.

Más todavía: así como en la periferia capitalista no es posible una forma de «desarrollo» distinta para América Latina, tampoco existe, dentro del capitalismo, ese lugar de «exclusión social» como un «afuera» en donde existen hombres y mujeres que no son susceptibles de recibir un valor como fuerza de trabajo y en tanto están «afuera», sin posibilidad de subjetivizar una posición antagónica con relación a esa norma de valorización. La falacia de la idea de la «exclusión», que hace del desempleo un lugar por fuera de la norma y no su resultado, preserva la hegemonía del valor-trabajo al tiempo que oculta la función clave que cumple el fenómeno de la «informalidad» socioeconó- 
mica en las relaciones capitalistas, disminuyendo costos de producción y realización en el ciclo de reproducción ampliada del capital.

La hipocresía con que se habla de la «exclusión social» como defecto y no como resultado necesario para sostener la tasa de ganancia en el capitalismo de la subsunción real del trabajo a escala mundial, cancela el barato ofrecimiento de las reformas «técnicas» y «humanitarias» compatibles con el orden burgués. Por el contrario, superar la barbarie que hasta ahora nos ha caracterizado como especie, requiere suprimir la máquina jurídica-institucional al servicio de la propiedad privada de los medios de producción, como una excrecencia que inhibe la superación de una humanidad dominada por la miseria del cálculo egoísta de la ganancia individual para beneficio de una minoría cada vez más exigua.

En este caso particular, la lucha por conquistar la hegemonía política que asegura la vigencia de las actuales relaciones de producción necesita no solamente verificar y denunciar las injusticias evidentes, siendo una de tantas, y no la mayor, la existencia de pocas, malas y peor distribuidas oportunidades para que los jóvenes sean capaces de desarrollar a plenitud sus posibilidades como grupo social, sino exponer y denunciar la base ideológica del razonamiento, cínico o ingenuo, que hace de la sociedad un mercado de bienes y servicios que puede llegar a proporcionar la anhelada «integración» juvenil, que en definitiva, y dentro de esta sociedad, sólo puede ser resignarse a ser explotados con creciente felonía o permanecer como rehenes que garantizan el bajo costo de la fuerza de trabajo empleada.

\title{
2. EL EMPLEO DE LA JUVENTUD (1): TRANSICIÓN Y JUVENILIZACIÓN
}

\author{
La juventud se encuentra \\ en el centro de lo nuevo \\ WALTER BENJAMIN
}

\section{UNO}

La mayor parte de los estudios realizados sobre el desempleo de los jóvenes comienzan por describir la transitoriedad de la condición juvenil, derivada del carácter provisional de esta edad, como si tales características no fueran comunes a todas las edades. Más que contentarse con perogrulladas, cabría pensarse que la transitoriedad de la 
condición juvenil está acentuada por la función biológica de la juventud en la reproducción de las generaciones, pero que en sí misma considerada, tal transición no define un rasgo esencial de la juventud. Aun así, esta transitoriedad ha constituido socialmente la edad juvenil a lo largo de casi toda la historia e influido las formas jurídicas e institucionales asociadas con la identificación, clasificación y control de la transición de este grupo a la edad adulta, siendo la sociedad burguesa, más que ninguna otra, donde la transición juvenil ha sido puesta bajo como disciplinamiento para asegurar su disponibilidad, alta calificación y buen precio en tanto fuerza de trabajo.

En el capitalismo, las condiciones de producción de la vida social o de los medios para producirla están mercantilizadas, es decir, son tratadas como si fueran mercancías, de acuerdo con la ley del valor. Sin embargo, algunas de estas condiciones no son «producidas» por el mismo proceso que convierte el resultado del trabajo humano en mercancía, sea porque se hallan en la naturaleza o porque necesitan inversiones que ningún capitalista puede realizar únicamente por su propia cuenta. Por esto, se necesita de un agente «externo» que asegure su existencia en las cantidades y calidades debidas, en el tiempo y lugar correcto, para ponerlas bajo el dominio de la ley del valor. Tal agente es el Estado capitalista y sus instrumentos de intervención, ${ }^{1}$ consolidados en un proceso histórico de progresiva expansión de sus funciones a áreas antes consideradas como dominio de decisiones privadas o comunitarias, muy por el contrario de lo que pregonan bienintencionados socialdemócratas, que rasgan las vestiduras republicanas ante una supuesta «reducción» del Estado con el que se identificaba el «buen» capitalismo. ${ }^{2}$

1 Existen ejemplos obvios para la actuación del Estado en beneficio de mejor acceso del capital a los factores de producción: así, para la fuerza de trabajo, las leyes laborales, la protección al binomio maternoinfantil, la promoción de la familia, la salud, la educación, la vivienda, la seguridad social, etc.; para el territorio, el ordenamiento urbano, el transporte, las comunicaciones, las limitaciones al uso de la tierra, las políticas de regionalización como las zonas francas o industriales, etc.; para la naturaleza, las medidas de protección (o desprotección) de especies, bosques, recursos hídricos, parques nacionales, etc.

2 Por el contrario, lo que se advierte es un desmesurado crecimiento de Moloch, en una especie de publificación de la esfera estatal en la llamada sociedad civil, al punto que el interés particular es a menudo superpuesto al interés común e identificado, sin más, con los principios que 
En nuestro objeto de análisis, se verifica que muchos de los cambios cualitativos operados en las estructuras del Estado capitalista a partir de la revolución industrial y el ascenso de la burguesía al poder político coinciden con la valorización de la juventud, como objeto y sujeto de una renovación política de las élites, ${ }^{3}$ que posteriormente se hizo extensivo a la clase trabajadora, ${ }^{4}$ a medida que las transformaciones de sociedades rurales y agrarias en sociedades urbanas e industriales demandaban una fuerza de trabajo más cualificada, disciplinada y homogénea, ${ }^{5}$ asociada a la escolarización de la adolescencia y la ju-

consagra el mercado como ente organizador de la vida pública y el consenso social. En otras palabras, nada hay más público que el valormercancía, y corresponde al Estado capitalista asegurar que esta publificación se extienda al mayor número de objetos y relaciones posibles: nada deja de valorarse en el mercado; es decir, nada es privado para la ley del valor, ley que el Estado capitalista asegura y mantiene.

3 Es particularmente relevante el ensayo de Jean-Claude Caron acerca de la relación entre la conformación de los Estados nacionales surgidos a partir del ascenso de la burguesía como poder económico y político, con el descubrimiento y afirmación, por parte de esa burguesía, del valorjuventud, y su fe en su educación e instrucción: «A través de la nacionalización proyectada de las redes escolares, la juventud pasó a ser la apuesta política y social [...] Desde una perspectiva más amplia y a nivel europeo, la segunda enseñanza aparece sin duda como el crisol donde se forjaron los hijos de una burguesía conquistadora: resulta sorprendente ver el paralelismo entre la constitución de los sistemas nacionales de segunda enseñanza y el ascenso de esas clases burguesas que, a través de lo económico y lo político, se fueron haciendo con las riendas de Estados en pleno auge y a veces en plena génesis. A esa "fabricación" de Estados respondía la "fabricación" de élites» (Caron, 1996:230-231).

4 Este proceso, que sólo se cumplió América Latina en el siglo XX, fue posible cuando la mayor parte de la formación o aprendizaje para el trabajo impartida a los jóvenes pudo ser costeada directamente por asalariados comprometidos para ello, principalmente docentes, y la parte restante, asumida por el conjunto de la patronal y de los asalariados a instancias de la recaudación impositiva destinada a sufragar los presupuestos para la instrucción pública.

5 Trasplantado por las élites criollas, el modelo europeo de Estado adopta especificidades propias que dan cuenta de su compleja constitución y su oposición a los intereses de la pequeña burguesía liberal y las incipientes masas populares de campesinos y esclavos. En este contexto, la escuela 
ventud, que prorrogó el período de dependencia económica propio de la infancia, en relación con su indefensión, a la formación profesional para el trabajo durante la adolescencia y la juventud. Tal intervención pública se concretó en instituciones, legislaciones y políticas que acompañaron la ampliación de la fase etaria juvenil. ${ }^{6}$ En otras palabras, la concepción de la juventud como etapa de transición para la etapa adulta y el diseño de las instituciones que regulan su incorporación a la sociedad adulta, no surgieron del proletariado ni fueron una conquista de la Ilustración, sino un resultado políticamente inducido por la burguesía en su conjunto, ante las necesidades del modo de producción capitalista.

\section{Dos}

Los estudios revisados sobre el tema del desempleo, la forma más insidiosa que se adjudica la preocupante «exclusión» juvenil de nuestras sociedades, justifican la necesidad de diseñar medidas especiales para fomentar su empleabilidad, aduciendo que tras profundizarse las diferencias con los adultos en el mercado laboral, se ha puesto en riesgo la estabilidad de las sociedades como efecto de una fractura en la transición generacional encarnada en los jóvenes. Esto acontece, no sin ironía, cuando los límites entre las edades juveniles y adultas se difuminan en una subjetividad compartida, donde la vivencia del presente y la percepción del porvenir empiezan a constituirse en torno a significantes e imaginarios propios de la edad juvenil, en una especie de juvenilización de la vida social.

Esta juvenilización no guarda sólo relación con la mercantilización del signo juventud, más que evidente en la exaltación publicitaria del vitalismo biológico propio de esta edad, sino más con la experiencia de una inestabilidad en los vínculos, del reciclaje permanente de las experiencias y del carácter provisional de todas las decisiones.

pública constituyó, quizás, la única institución capaz de agenciar con mediana eficacia un discurso de integración nacional en países recién conformados, con más territorio que Estado y más pobladores que ciudadanos.

6 «Na transiçao das sociedades agrárias para as sociedades urbanas e industriais, aparecem medidas de interferencia pública voltadas para a emancipaçao da crianza e do adolescente da condiçao de trabalho para a sobrevivência» (Pochmann, 2004:217-218). 
Esto es particularmente visible en la producción de las subjetividades adultas ligadas al trabajo asalariado: así la identidad profesional que se organizaba alrededor de un empleo seguro y estable, parece constituirse en una utopía, es decir, un no-lugar, al que por definición nunca se llega, mientras emergen nuevas subjetividades del trabajo, movilizadas por una relación salarial precaria, insegura e inestable, que se nutre de identidades permanentemente renovadas, acosadas por la constante pérdida de su valor en el mercado.

En este sentido, las reformas de las leyes de previsión social -falsamente justificadas por constataciones «científicas» sobre el envejecimiento de la población, la relativa disminución de las contribuciones privadas a los sistemas de seguridad social y el desempleo estructural como fenómeno mundial - se orientan a mercantilizar los fondos públicos de pensiones, extender las edades de jubilación y rebajar los costos del salario, trasladando al salario una mayor proporción de los gastos para el mantenimiento y la reproducción social de la fuerza de trabajo al trabajador y su familia, proporcionando adicionalmente los capitales financieros — provenientes del ahorro de millones de asalariados - a los especuladores financieros.

En este marco, complementado por el incremento de la productividad y descenso de la tasa media de ganancia a nivel mundial, las transformaciones sociodemográficas, relacionadas con el aumento de la longevidad y la disminución de las tasas de natalidad, provocan un menor canon de dependencia, y por lo tanto, derivan en el incremento proporcional y absoluto de la población económicamente activa en las sociedades y determinan un estado permanente de sobreoferta de la fuerza de trabajo en el mercado laboral.

Así es como cada vez más jóvenes buscan cualquier empleo por menos del salario mínimo, sin prestaciones sociales ni estabilidad laboral, compitiendo con grupos que padecen una situación similar, como las mujeres o las personas desempleadas mayores de 40 años, en un contexto que podríamos caracterizar como de «juvenilización» de sus condiciones de trabajo, pues para todos coincide el conjunto de medidas para fomentar la empleabilidad (la calificación orientada hacia la polivalencia de funciones combinada con la flexibilización en las formas de contratación y la creación de categorías salariales «excepcionales»), que tienden a convertirse más en la regla que en la excepción. Puede decirse que con relación al empleo, la juventud representa la metáfora del presente de la sociedad capitalista y, al mismo tiempo, la visión de su futuro, lo que justifica con creces el epígrafe de este artículo: la juventud se encuentra 
al centro de lo nuevo. Y lo peor es que ni a corto ni a largo plazo es posible otro desenlace dentro del capitalismo. ${ }^{7}$

De esta manera, sin someterse a las fatigas del gimnasio y los penosos planes quinquenales de cirugía estética que padece la burguesía para conservar la juventud como signo, una vez más el capitalismo, haciendo alarde de su contradictoria vocación igualitaria, rejuvenece a los trabajadores, imponiéndoles la vivencia permanente de una inminente obsolescencia y la persistente necesidad de una renovación constante, la misma que anima, bajo el signo de la moda, el significante de lo juvenil en el consumo capitalista: la enorme riqueza social producida por el incremento de la fuerza productiva del trabajo humano, que se nos presenta como un cúmulo extraordinario de mercancías que necesitan ser consumidas con más rapidez y a un precio relativamente menor en cada ciclo de producción, hallando, como contrapartida, el incremento de la mercancía fuerza de trabajo y la disminución de su costo (que incluye, como no, las múltiples formas del «autoempleo»), bajo la amenaza de la provisionalidad que caracteriza a todos los productos del mercado.

\title{
3. EL EMPLEO DE LA JUVENTUD (2): SALARIO Y REESTRUCTURACIÓN CAPITALISTA
}

\author{
Para no hacer de mi icono pedazos, / para \\ salvarme entre únicos e impares, / para cederme \\ un lugar en su Parnaso,/ para darme un \\ rinconcito en sus altares/ me vienen a convidar a \\ arrepentirme, / me vienen a convidar a que no \\ pierda, / me vienen a convidar a indefinirme, \\ Ime vienen a convidar a tanta mierda. \\ SILVIO RODRÍGUEZ
}

7 «Un sacerdote decía "nosotros podemos tener nuestros planes, nuestros proyectos, pero ¿qué importan nuestros planes y nuestros proyectos? Lo que importa son los planes y proyectos de Dios. Uno puede tener un plan de trabajar hasta los 70 años y resulta que después no encuentra trabajo". Sin darse cuenta, este sacerdote vino a demostrar, con precisa elocuencia, los límites económico-sociales que el Dios Capital se pone a sí mismo para pasar por encima de ellos, toda vez que el proletariado no se atreva a ponerle límites políticos absolutos; en este caso, el capital se apresta a pasar por encima de las menguadas ilusiones y el propio cadáver de los ancianos, obligados a trabajar hasta la muerte» (GPM, 2003:14). 


\section{UNO}

De forma similar a las representaciones idealistas de la juventud, los análisis predominantes del desempleo juvenil consideran el fenómeno de manera aislada y descriptiva, sin reparar en las contradicciones capitalistas y su influencia sobre las relaciones institucionales y político-jurídicas que rigen las nuevas formas de organización y división internacional del trabajo. Sin embargo, es el contexto del desempleo juvenil, y no el desempleo en sí mismo, el que debe ser articulado a la totalidad del mundo laboral, con sus múltiples relaciones y contradicciones, y la manera como se afecta por la reestructuración del capitalismo a escala mundial. Para hacer explícitas estas cuestiones y revelar su dinámica, es necesario situar las políticas de empleo juvenil en América Latina como efecto de la transición mundial de un capitalismo predominantemente fordista en la organización social del trabajo, con su respectiva forma-estado, a un capitalismo postfordista y su forma-estado correspondiente, diferenciado por distintas condiciones de acumulación capitalista y mecanismos específicos de regulación y control de la lucha de clases.

La organización del trabajo y las instituciones reguladoras propias del fordismo coinciden con la onda expansiva del capitalismo después de la segunda guerra mundial, pero fueron preparadas por la depresión de la década del 30. Su instauración en América Latina tiene especificidades propias, tanto en los aspectos económicos como en los político-institucionales, particularidades derivadas de la industrialización dependiente de los grupos asociados a la burguesía agroexportadora, cuyas relaciones con el capital internacional eran necesarias para adquirir los bienes de capital y bienes durables de consumo que demandaba su ciclo de rotación. Así, y a diferencia de Europa, la naciente burguesía industrial latinoamericana no realizó una revolución política a la par de la «sustitución de importaciones» y la industrialización de la economía, destinada a extirpar el sistema político anterior y las antiguas relaciones de producción, sino que, en ausencia de la acumulación primaria y otras condiciones del desarrollo capitalista europeo, se limitó a conciliar su emergencia como clase con el mantenimiento del acceso a los recursos externos que proporcionaba la economía agroexportadora, cuyas clases fueron preservadas.

Tal forma de acumulación se institucionalizó mediante la alianza nacional-populista entre la flamante burguesía industrial y las incipientes clases asalariadas urbanas, que dejaron intactas las relaciones 
de producción del modelo agroexportador, cuyos excedentes de fuerza de trabajo - emigrada a las ciudades en el rápido proceso de urbanización que caracterizó el siglo XX latinoamericano ante el cambio de «modelo» de desarrollo-, en ausencia de una «acumulación primaria» para financiar un sector terciario capaz de realizar la totalidad de la producción industrial y agropecuaria, fungió como «microempresariado» que, sin apenas capitalización, asumió la tarea de comercializar los productos industriales y agropecuarios por fuera de los costos internos de producción, reforzando la reproducción ampliada de capital en las unidades centrales del sistema (Oliveira, 1977:29-36) y estableciendo las bases del sector de «servicios», tan informal y precario como fundamental en la dinámica del capitalismo latinoamericano y, consecuentemente, para la generación de empleo. ${ }^{8}$

Durante este período, los presuntos logros del «Estado capitalista-empresario de bienestar», influenciaron las experiencias de los gobiernos nacional-populares en los países del «tercer mundo», en un escenario mundial favorable para la ilusión de una «iustitia distributi$v a »$ capitalista, ${ }^{9}$ mediante políticas económicas «redistributivas» de

8 Como explica Oliveira (1977), las revoluciones burguesas europeas, en que la hegemonía asfixiante de las clases propietarias rurales paralizaba cualquier desarrollo de las fuerzas productivas en ausencia de cualquier relación «externa» que les suministrara los bienes de capital necesarios para la reproducción ampliada del capital, impuso a la burguesía la tarea histórica de realizar una ruptura con el anterior orden para «liberar» las fuerzas productivas de las opresivas relaciones de producción precapitalistas e instaurar la hegemonía salarial en las nuevas relaciones de producción. Sin embargo, mientras la fuerza laboral nacional en los países europeos se hacía cada vez más proletaria mediante la expansión del trabajo asalariado y la relación contractual entre individuos formalmente libres e iguales, la opresión colonial y la esclavitud aumentaban en los puestos de avanzada del capitalismo. En realidad, la ideología que en los planos jurídico y político niega la desigualdad y la falta de libertad fundamentales de la relación económica capitalista, siempre ha sido un elemento clave de la hegemonía del capitalismo, cuya verdad desnuda se expone, como siempre, en la periferia y márgenes del sistema.

9 Estas condiciones están comprendidas en el supuesto que Marx desarrolla en el punto 1, capítulo XXIII, Libro I de El capital, «demanda creciente de fuerza de trabajo, con la acumulación, manteniéndose igual la composición orgánica del capital»; no fue pues ningún «milagro» de la política económica implementada por los Estados-empresarios, sino producto de la necesidad histórica del capitalismo, presidida por la ley de la acumulación, en 
una economía «mixta»: tal es el signo político del Estado populista en América Latina, responsable de acondicionar las bases materiales e ideológicas, ${ }^{10}$ para la flamante burguesía industrial de cuño nacionalista. De esta forma, sin mediar una verdadera revolución política, las divisas provenientes de la exportación de productos primarios, el aumento del consumo interno en las ciudades y la disminución de los costos de la fuerza de trabajo empleadas en los sectores primarios y terciarios, financiaron, subsidiaron y protegieron el crecimiento de industrias locales para atender el mercado doméstico, al tiempo que se realizaron inversiones en infraestructura, comunicaciones y reproducción de la fuerza de trabajo (salud, educación, vivienda, principalmente) que promovieron la fantasía de una «ciudadanía social» compartible con el capitalismo. ${ }^{11}$

Con todos sus sesgos y deficiencias, ${ }^{12}$ para conquistar un desarrollo capitalista «maduro», este modelo sostuvo un desarrollo institucional que entonces resultó rentable para ambas clases en pugna: el Estado planificador incorporaba el conflicto de clase como motor del crecimiento económico en torno a la lucha por el incremento del salario relativo de los trabajadores mejor posicionados, ${ }^{13}$ cuyos efectos se

condiciones de aumento más que proporcional de la demanda de trabajo respecto de los medios de producción (maquinaria, edificios, materias primas y auxiliares) empleados durante la reconstrucción europea y Japón, en el contexto de la conversión de la economía de guerra a la de paz, que licenció y reincorporó a los soldados como acervo de capital variable en países empobrecidos por la guerra y la pérdida de vidas humanas (los muertos de la segunda guerra mundial ascendieron a más de 30 millones).

10 La industrialización, la asalarización de las relaciones de producción y la conformación de una fuerza de trabajo para la sustitución de importaciones y el «desarrollo hacia adentro».

11 En América Latina se incrementaron, de forma casi constante, al menos por tres los ingresos per capita de la población, se duplicaron los años de escolaridad de la población, se redujo la mortalidad infantil hasta menos de la mitad, y aumentaron un promedio de veinte años las expectativas de vida para hombres y mujeres.

12 Graves desequilibrios en la balanza de pagos, resultantes del drenaje provocado tanto por las inversiones y préstamos del exterior, tanto como por la misma dinámica de una industrialización sustitutiva y dependiente que al tiempo que libró a la región de ciertas importaciones creó la necesidad de otras, mucho más costosas.

13 Es decir, los trabajadores asalariados, con un fuerte protagonismo de los sectores urbanos vinculados al funcionariado público, las empresas del 
transfirieron a políticas sociales universales con consecuencias unificadoras de las clases trabajadoras, si bien políticamente subordinadas a una relación salarial coexistente con un mercado laboral informal, cuyas dimensiones, siempre significativas en comparación con los países de relaciones capitalistas más consolidadas, servían para mantener el bajo costo de la fuerza de trabajo en la región. ${ }^{14}$

En este contexto, se puede admitir una situación socialmente favorable para los jóvenes como grupo social, que sin desconocer las notorias desigualdades entre regiones, clases y fracciones de clase, permitían un horizonte de ascenso social y mejora en los estándares de vida, inscritos en las instituciones de transición al mundo adulto, como la escuela y el empleo. ${ }^{15}$ Concretamente, la expansión de la educa-

Estado y las grandes industrias, agrupados en torno a relaciones de producción con categorías salariales más homogéneas.

14 Siguiendo a Oliveira, que en 1975 analizando el caso brasileño atribuía una función ideológica a las teorías que hacían del subdesarrollo una fase histórica del capitalismo y no una formación capitalista propia de la dinámica de acumulación en los países con una inserción periférica, resulta fácil desmontar las modernas concepciones del desarrollo que atribuyen la precariedad del Estado social en América Latina a formas «premodernas» de desarrollo institucional. Por el contrario, al sostener que la universalización de los derechos requiere, como paso previo, la constitución de un polo de clase asalariada capaz de exigirlos, la explicación de las diferencias no son producto de las deficiencias institucionales de las democracias del Tercer Mundo sino del restringido proceso de salarización en los países del sur, correlacionado con un consumo de masas igualmente limitado. En tal sentido, no hay lugar a esperar una suerte de «evolución» de las formaciones capitalistas subdesarrolladas hacia un modelo más desarrollado, sino una suerte de mutación divergente o, en palabras del propio Oliveira, una «singularidad histórica» propia del desarrollo capitalista en las ex colonias, una vez convertidas en periferia del sistema mundial y proporcionar los inputs para la acumulación de capital en el centro de la economía-mundo capitalista. Esta relación, que se mantiene incluso a través de drásticas transformaciones, es lo que impide a las antiguas colonias «evolucionar» y alcanzar las etapas superiores de la acumulación capitalista; es decir, ponerse a la altura del centro dinámico, «por muy a menudo que recibieran inyecciones de modernización desde éste» (Oliveira, 2004:37).

15 Las políticas de juventud, como bien dice Ernesto Rodríguez (2004:99), funcionaron «con cierta fluidez en el marco de economías expansivas y dinámicas, que aseguraban cierta movilidad ascendente, sobre todo para 
ción formal, pieza clave del Estado-empresario latinoamericano, extendió la «moratoria social» del joven a las clases trabajadoras, y junto con el mejoramiento del consumo, la masificación de la televisión y el impulso de poderosas industrias culturales, facilitaron los fenómenos de subjetivación e identidad juvenil que reivindicaron un punto de contraste generacional con la herencia cultural adulta, cuyos rasgos más universales estaban en el cambio de las costumbres asociadas a la sexualidad y las relaciones afectivas, la aparición de consumos culturales específicamente juveniles, y el ascenso de la participación y la organización política de los estudiantes.

\section{Dos}

Una vez reiniciado el proceso de acumulación, con el paulatino aumento de la masa de capital en funciones, al que por efecto de la competencia se le fueron incorporando los adelantos tecnológicos aplicados a los armamentos, el consecuente aumento en la composición orgánica del capital fue acercando el horizonte de una nueva crisis de superproducción absoluta de capital, que se puso de manifiesto en 1971, inmediatamente después de la inconvertibilidad del dólar. En ese marco, las condiciones de reproducción ampliada del capital, ante la tendencia siempre decreciente de la tasa de ganancia, imponen la constante reestructuración de los márgenes de beneficio del empresario capitalista mediante el despliegue de políticas monetarias antiinflacionarias por parte del Estado, la flexibilización de las relaciones laborales, y la introducción de nuevas formas de organización del trabajo: cortes irreversibles en el gasto público social, desempleo y control en el aumento de los salarios, aumento en la concentración de los medios que garantizan el flujo de capitales y la circulación de las mercancías, combinado con el financiamiento selectivo de sectores industriales que permitan una rotación más rápida del capital.

Este proceso, que cuestiona la ideología que explica la «globalización» como el resultado de un desarrollo tecnológico «natural», se explica por la crisis política irreversible del capitalismo fordista y sus modos específicos de regulación de los conflictos entre el capital y el

los jóvenes integrados, pero mostró serias limitaciones para responder a la problemática de los jóvenes excluidos, especialmente en las etapas de crisis». 
trabajo. ${ }^{16}$ Tal crisis debía ser «exportada» mundialmente, ampliando las relaciones capitalistas de producción más allá de los países donde la relación salarial y las grandes industrias eran elementos centrales de la economía: su «solución» fue la intensificación, a escala mundial, de la desreglamentación de las normas de circulación del capital, la deslocalización del capital industrial y financiero, y el uso intensivo de los avances tecnológicos en informática y robótica, pero especialmente se realizó por la «flexibilización defensiva» de la relación salarial, que permitió la disminución de los costos laborales, como la única forma de sostener la acumulación capitalista y la viabilidad de la ley del valor vigente.

Tal disminución del capital invertido en salarios sólo se hizo posible al combinar la superproducción con la cada vez más alta composición orgánica del capital en funciones, que ocasiona el incremento de la productividad del trabajo humano al aplicarse sobre medios de producción más eficaces y costosos. En este contexto, la disminución en el aumento de la oferta en el mercado de medios de producción (máquinas, edificios, materias primas y auxiliares) determina, automáticamente, la disminución relativa de la demanda de salarios en el mercado de trabajo, que comenzó a crecer menos que el aumento del capital constante y de la población asalariada. Así, la creciente formación de un capital ocioso, que inicia un ciclo de la mal llamada «especulación financiera», tuvo como contrapartida el desempleo estructural masivo y la precarización de todas las formas de relación salarial, cuyos costos, ahora liberados, se destinaron a financiar los sectores industriales o agroexportadores que mejor pueden reproducir y ampliar, a escala mundial, el capital invertido.

Sin embargo, en el contexto de la división internacional del trabajo, la reducción de los costos de la fuerza de trabajo y la liberación del gasto público social asociado a su reproducción, concurren ya no apenas en la modesta periferia del sistema, sino en su mismo centro, invadiendo todos los márgenes e intersticios de la producción capitalista, para el desarrollo de las ventajas competitivas (productividad del

16 Desencadenada en el régimen de acumulación capitalista tanto por la superproducción y la caída continuada de la tasa de ganancia, como por la valorización del salario como instrumento de lucha para los trabajadores, ocasionaron el déficit fiscal y de legitimidad del Estado Benefactor como instancia para asegurar el nuevo régimen de acumulación postfordista y su perentoria transformación al Estado neoliberal. 
trabajo y plusvalía relativa), asociadas a factores de valor agregado en la producción de bienes de capital en combinación con las ventajas comparativas (intensidad del trabajo y plusvalía absoluta) para la producción de bienes de consumo y materia prima, sobre la base del aumento de la intensidad y extensión de la jornada de trabajo impaga. En otras palabras, la aplicación de la alta tecnología combinada con reducción de costos de la fuerza de trabajo - es decir, plusvalía relativa y plusvalía absoluta - que se verifica a escala mundial, aumenta la productividad del trabajo y la tasa de explotación a niveles nunca vistos, al tiempo que genera crisis de superproducción y realización del capital, que para mantener sus márgenes de lucro e incrementarlos, por efecto de la centralización de capitales, deben trasladarse, forzosamente, a la destrucción de puestos de trabajo. ${ }^{17}$

Sin embargo, esta ruina debe tener un límite pues, como expresa Mandel (1979), el capitalismo, en tanto unidad contradictoria de empresas no automatizadas, semiautomatizadas y automatizadas, debe oponer una creciente resistencia a la automatización después de cierto límite, ya que su existencia necesita la relación salarial para la producción de valor y, por ende, de plusvalía. ${ }^{18}$ Las consecuencias de esta

17 «Las tesis, marxistas o no - como las que esbozaron las corrientes endogenistas y neodesarrollistas - que interpretaron el planteamiento de la teoría de la dependencia en el sentido de que las sociedades dependientes estaban imposibilitadas para desarrollar el capitalismo sobre la base del desarrollo de la productividad, no sólo son falsas, sino que su planteamiento sólo es válido en un alto nivel de abstracción. En realidad los mecanismos de la plusvalía absoluta y relativa se combinan, cuestión que no entendieron las corrientes mencionadas. A diferencia del primer modelo de sociedades en el cual el valor de la fuerza de trabajo se modifica por la incorporación de tecnología de punta, que es el motor de la plusvalía relativa, en las sociedades dependientes el aumento de la productividad del trabajo que resulta de dicha incorporación se traduce en una intensificación del proceso de explotación del trabajo, acentuando la superexplotación del trabajo [...] Ejemplo de ello son el errático comportamiento de los salarios $\mathrm{y}$, por ende, de la distribución de los ingresos, así como el desempleo, el subempleo, la precarización del trabajo, la exclusión social y la extensión de la pobreza en todas sus facetas y ramificaciones dentro de las sociedades capitalistas dependientes y subdesarrolladas» (Sotelo, 2003:18).

18 Lejos de la idealizada sociedad de las novelas de ficción y de los teóricos del «fin del trabajo», en que las máquinas realizan el trabajo de todos los hombres, los cuales sólo deben pensar, el capitalismo no puede 
contradicción fueron anticipadas tan claramente por Marx, que hacen innecesario agregar más explicaciones: «El desarrollo del régimen capitalista de producción y de la fuerza productiva del trabajo - causa y efecto a la par de la acumulación - permite al capitalista poner en juego, con el mismo desembolso de capital variable, mayor cantidad de trabajo, mediante una mayor explotación, extensiva o intensiva, de las fuerzas de trabajo individuales. Y hemos visto asimismo que, con el mismo capital, compra más fuerza de trabajo, tendiendo progresivamente a sustituir los obreros hábiles por otros menos hábiles, la

existir sin la explotación del trabajo asalariado. Marx distingue entre capital constante (medios de trabajo y materias auxiliares) y capital variable (salarios), porque cada una de estas dos partes del capital invertido tiene un comportamiento distinto en el proceso de producción. Por un lado, el capital constante transfieren íntegramente su valor al producto resultante: si 1 kilo de lana necesario para hacer una camisa tiene un valor dinerario de 100 pesos, este kilo de lana añade a la camisa un valor de 100 pesos, ni uno más ni uno menos. En lo que respecta a las máquinas, edificios, estructuras, etc., éstos transfieren su valor al producto terminado de forma parcial y proporcional, según su desgaste por el uso o consumo productivo. Es lo que técnicamente se conoce como «amortización». Esto quiere decir que el valor de los medios de trabajo y de las materias primas permanece constante antes y después de intervenir en el proceso productivo. El valor que pierden por el uso, reaparece en cada producto terminado. No añaden más valor del que ellos mismos poseen independientemente del proceso de producción al que pertenecen.

Otra cosa acontece con la fuerza de trabajo, que es una mercancía singular dado que es la única cuyo uso agrega valor. Al trabajar, el asalariado ejecuta las siguientes operaciones: i) Consume su fuerza de trabajo a la vez que recrea su valor, el equivalente de su salario, de lo que necesita para vivir y seguir trabajando en condiciones óptimas. ii) Conserva el valor de los medios de producción que utiliza, al transferirlos productivamente a la mercancía (la tecnología no crea valor, sino su aplicación mediante el operario de la tecnología). iii) Crea plusvalor para el patrón, que es la finalidad del capital, al realizar trabajo impago. A diferencia del capital invertido en los medios de trabajo y en las materias primas, cuyo valor se mantiene constante, la fuerza productiva en acción, el trabajo del asalariado, convierte la parte del capital invertida en salarios en una magnitud variable en la medida del plusvalor producido durante la jornada de labor, cuya variación depende de la tasa de explotación. 
mano de obra madura por otra incipiente, los hombres por mujeres, los adultos por jóvenes o niños» (Marx, 2000:538).

Que este proceso no se haya verificado de manera inmediata y sin resistencia del proletariado, incluso con el apoyo de ciertas facciones burguesas en decadencia, ${ }^{19}$ respalda la idea, contraria a los reparos que hacen los teóricos de la globalización, de la plena vigencia y necesidad del Estado Nacional: las políticas siguen siendo, fundamentalmente, politicas de y entre Estados, incluso aquellas menos desarrolladas institucionalmente, como es el caso de las políticas de juventud. Sin embargo, ahora están más evidentemente determinadas por el contexto de la competencia internacional: obviamente se ha producido un cambio en la función de los agentes estatales de las burguesías locales, ahora definitivamente ocupados en emplear sus recursos coactivos y coercitivos de poder, material y simbólico, para cautivar y retener los capitales de la burguesía internacional, generando las mejores ventajas «comparativas» y «competitivas». En este contexto, la aplicación de políticas públicas está supeditada, más allá de los discursos, a i) dis-

19 La tendencia histórica del gran capital va en el sentido de apoderarse de los capitales medios residuales para darles empleo productivo (producción de plusvalor) en condiciones técnicas de mayor desarrollo relativo. Esto explica la lucha militar contra las facciones nacionalistas cuyos intereses son incompatibles con el gran capital y el apoyo a las burguesías que pasan por serios problemas para mantenerse en el poder. Así, se suceden la invasión a Santo Domingo (1963) y los golpes de Estado en Brasil (1964), Indonesia (1965), Chile (1973), Argentina (1976) y Bolivia (1981), pasando por la desintegración política de la ex URSS y sus satélites en Europa del Este (1989/91), y recientemente, la intervención armada y desintegración política de Yugoslavia, Afganistán e Irak. En un segundo momento, despejado el camino de los incordios que impiden cumplir con las exigencias del capital, los gobiernos civiles que emergieron del retiro de las dictaduras, en las llamadas «transiciones democráticas», se propusieron como objetivo explícito reestructurar las relaciones sociales y laborales para hacerlas funcionales a las nuevas condiciones de acumulación y valorización del capital, aliando las burguesías locales e internacionales con la burocracia sindical, para aplicar las reformas necesarias en las condiciones de contratación, uso y despido de la fuerza de trabajo, desmonte de garantías y prestaciones económico-sociales y desregulación de los salarios, reduciendo el marco de acción legal y político de los sindicatos y fortaleciendo el poder de las gerencias sobre el mundo del trabajo... «itodo en defensa del empleo!», claman empresarios, gobierno y sindicatos. 
minuir el costo de la reproducción social de la fuerza de trabajo, y ii) consecuentemente, disminuir el costo de la mercancía «fuerza de trabajo humano». ${ }^{20}$

\section{TRES}

La alta tecnología y la automatización sólo tienen un carácter restringido y limitado a los países centrales y las ramas avanzadas de la producción industrial de los países periféricos, con una aplicación productiva cada vez más importante del conocimiento científico-técnico, al tiempo que generan y necesitan una «superpoblación» de trabajadores que alimenta el sector informal de la economía, con cadenas productivas, sectores y oficios sumidos en sistemas combinados de producción y explotación intensiva/extensiva, con mínimos costos de producción, donde realmente se generan la mayoría de los puestos de trabajo para los jóvenes, en tanto parte del proletariado.

Tal es la realidad de la «sociedad del conocimiento», el «vestido» nuevo del rey que descubre la desnuda verdad del capitalismo a quien quiera verlo, fantasiosamente presentada como la gran oportunidad de inserción sociolaboral de los jóvenes, ${ }^{21}$ no obstante las «paradojas» de su creciente exclusión actual.

Los principales signos de estos tiempos son la institucionalización del cambio y la centralidad del conocimiento como motor del crecimiento, $\mathrm{y}$ ambos factores colocan a la juventud en una situación privilegiada pa-

20 Reformas tendientes a la liberalización y privatización de los sectores económicos públicos, la estabilidad macroeconómica a costa de la sobrevaluación, el desempleo y la caída del consumo interno, la supeditación de las políticas sociales a las políticas económicas, la desregulación de las entradas y salidas de capitales y productos, la flexibilización de la contratación laboral y el mantenimiento de bajos niveles de sindicalización, el mejoramiento selectivo de las redes viales, aeropuertos, puertos y comunicaciones, la calificación y «docilidad» de la fuerza de trabajo, y el reforzamiento de la capacidad de aseguramiento policivo del orden burgués.

21 «Desde o último cuartel do século XX, quando se consolida uma nova transição das sociedades industriais para as chamadas sociedades do conhecimento, tem sido aberta uma oportunidade histórica de libertação da juventude da condenaçâo ao trabalho pela sobrevivência» (Pochmann, 2004:218). 
ra aportar al desarrollo. Así, la juventud pasa a ser el segmento de la población cuya dinámica se acompasa naturalmente al ritmo de los tiempos, mientras que lo contrario sucede con la población adulta [...] Sin embargo, mientras el despliegue de los actuales estilos de desarrollo exigen un aprovechamiento óptimo del tipo de activos que se concentran en la juventud, se da la paradoja que aumenta la exclusión social entre los jóvenes, destacándose como principal evidencia las importantes tasas de deserción y fracaso escolar y los elevados niveles de desempleo juvenil en la región (Rodríguez, 2004:80-81).

Procesos enunciados en el párrafo como verdaderas causas eficientes, tales como la «institucionalización del cambio» o la «centralidad del conocimiento», dan cuenta de «realidades» que sólo pueden ser reconocidas y aceptadas a condición de despilfarrar el «aprovechamiento óptimo» de los «activos» de la juventud: no hay sujeto a cargo del «despliegue de los actuales estilos de desarrollo» ni posibilidad de historia ni sentido alguno para la misma; todo se «acompasa naturalmente» y sólo se puede describir el «ritmo de los tiempos», promoviendo la legitimación de hechos estáticos, sancionados como «realidades» incontestables, sin contradicciones ni sujetos ni historia, es decir, sin movimiento.

Sin embargo, es la no intelección de tal movimiento lo que hace que tales «realidades» aparezcan como una cruel paradoja, aunque en verdad no sean sino la consecuencia lógica del desarrollo de las leyes económicas que rigen el modo de producción capitalista en la periferia del sistema. En otras palabras, el capitalismo no puede ser nada distinto de lo que es - desigualdad creciente, desempleo y criminalidad-, mientras el poder político siga instrumentalizado por las necesidades que impone la dinámica de acumulación y reproducción del capitalismo: la extensión de la ley del valor y la explotación del trabajo social a todas las relaciones humanas, en todas partes del mundo.

\section{EL EMPLEO DE LA JUVENTUD (3): POLÍTICAS PÚBLICAS Y DESINSTITUCIONALIZACIÓN JUVENIL}

Lo que me resulta chocante en vuestro razonamiento es que no trasciende el esquema del «hasta hoy». Pero la empresa revolucionaria no se dirige precisamente sólo contra el hoy, sino contra la ley del «hasta hoy». MiCHEL FOUCAULT 


\section{UNO}

La transición del capitalismo fordista a un sistema postfordista, como pérdida de su hegemonía hacia formas de organización social del trabajo más flexibles y heterogéneas, ha conllevado a la pérdida de la relevancia que tenían las instituciones reguladoras del tránsito de la juventud hacia el trabajo y su función «integradora»a la sociedad adulta, arrastrando la condición juvenil a un estado de desinstitucionalización, ${ }^{22}$ como contrapartida lógica necesaria del fenómeno de juvenilización mencionado. En este marco, las instituciones políticoadministrativas de producción social de la juventud son el lugar de batalla donde se dan las crisis de dominio y las formas de las resistencias y prácticas contrahegemónicas que encarnan generacionalmente como expresiones de una «anomia estructural», que Rodríguez describe, nuevamente en forma acertada, como producto de la dificultad del sistema educativo y la inserción laboral para funcionar como «transmisores de normas y valores que ordenan la vida cotidiana, estructuran aspiraciones y definen metas a alcanzar», cuya ineficiencia «impide que los jóvenes aporten al funcionamiento de la sociedad» (Rodríguez, 2004:80-81).

La desinstitucionalización de la juventud, que es la expresión generacional de la crisis institucional de la forma-estado del capitalismo postfordista, ha sido acompañada por la creciente plétora de políticas sociales que definen sus destinatarios más por identidades extraeconómicas (políticas de juventud, de mujer, de identidad racial) que por

22 Como causas/efectos inmediatos de esta desinstitucionalización, se pueden enumerar las siguientes (Abad, 2002): i) La crisis de la familia tradicional y la multiplicación de nuevas formas de familia, que cuestionan y replantean los límites y roles entre padres e hijos. ii) El agotamiento de la ilusión de ascenso social que se depositó en la expansión de la educación secundaria y universitaria. iii) La pérdida de relevancia política de los mecanismos de la democracia representativa y el sistema de partidos. iv) La disolución de las identidades ligadas a una reproducción estable y ordenada de la cultura «nacional» en las nuevas generaciones. v) La relativización de las edades de la vida en relación con las trayectorias vitales, especialmente las que definían el tránsito entre familia-escuela-empleo. vi) La consolidación de una paideia informática

y mediática, en paralelo, sustitución o contradicción con las instituciones tradicionalmente a cargo de la transmisión cultural, es decir, la familia, la escuela y el empleo. 
clase, destinadas a atender selectivamente las distintas formas de opresión extraeconómica (colocadas por fuera de las relaciones capitalistas de producción) que padecen.

Sin embargo, como las identidades extraeconómicas incorporan sectores específicos de las clases trabajadoras — nadie está excluido del trabajo asalariado como destino, salvo la burguesía - las medidas compensatorias de las desigualdades facilitan la disminución de los costos de la fuerza de trabajo y de la reproducción social, al tiempo que hacen parecer que su explotación y discriminación se debe a causas ideológicas ajenas a la lógica necesaria del sistema capitalista. De ahí que la ideología burguesa aísle e intervenga separadamente, clase a clase, la reproducción social de las generaciones. Cuando Bourdieu (1990) dice que «una clase o fracción de clase está en decadencia, y por consiguiente orientada al pasado, cuando no está en condiciones de reproducirse con todas sus propiedades» y en tal caso, los conflictos generacionales «tienen por principio la oposición entre los valores y los estilos de vida», está expresando, en otras palabras, la ideología reaccionaria que confina el conflicto generacional al interior de una clase.

De esta manera, el problema del empleo juvenil es el resultado de un obstáculo corporativista con los adultos al interior de una clase, donde las generaciones «ya integradas a la dinámica societal», están «escasamente dispuestas a facilitar la incorporación de las generaciones más jóvenes a esa compleja dinámica» (Rodríguez, 2002). En efecto, Tokman (2003) menciona, entre las causas del desempleo juvenil, sólo una que tiene relación con el crecimiento económico; las restantes, directa o indirectamente, son atribuibles a factores «generacionales»: el desajuste entre las expectativas juveniles y las ofertas de empleo, el escaso «capital humano» de las nuevas generaciones y la regulación inadecuada del mercado laboral. Sus recomendaciones, en esa misma línea, consisten, además de la recuperación del crecimiento económico y el pleno empleo, el mejoramiento de la educación formal con medidas especiales de capacitación y «primer empleo», y la adecuación del mercado laboral para los jóvenes, mediante la flexibilización de la contratación y la reducción de costos de la mano de obra juvenil, vía subsidios o disminu\&iónedibartgodemás delaliieorsaños de políticas de empleo juvenil en América Latina han puesto en evidencia tres desconexiones fundamentales: i) la educación, tanto la formal como la compensatoria, no mejora los índices de ocupación de los jóvenes; ii) tener un empleo no es garantía de un ingreso satisfactorio para las nuevas generaciones; 
iii) ni el crecimiento económico ni la estabilidad macroeconómica son generadores de puestos de trabajo para los jóvenes (ni tampoco para los adultos); tales programas de empleo, cuando tuvieron éxito, consiguieron disminuir el tiempo de «paro» en el desempleado juvenil, lo que hace suponer que la capacitación, combinada con la disminución de los salarios y el traslado de los costos de la reproducción social a las familias de los trabajadores, permiten «adelantar puestos en la fila» de los desempleados. Pero aun cuando los conocimientos, destrezas ocupacionales y habilidades sociales de empleabilidad mejoran la competitividad de los jóvenes frente a otros asalariados (aunque la competencia sea cada vez más cruenta y la fila de desempleados más larga), los bajos salarios percibidos y la inestabilidad de los puestos de trabajo (apoyados por las medidas que favorecen la flexibilización de la relación salarial) no favorecen que los jóvenes puedan hacer del empleo una forma de proyección social como lo fue para sus abuelos, y quizás para sus padres. ${ }^{23}$

En cambio, las estrategias para generar empleo juvenil, especialmente las que estimulan directamente al sector privado para la contratación de jóvenes, que combinan capacitación, beneficios tributarios y desregulación laboral, han reforzado los componentes de una relación salarial cada vez más precaria, desigual e insegura, consiguiendo que coyunturalmente el desempleo disminuya en las estadísticas sólo para integrarse en las categorías de subempleo, «producción flexible», working poors, trabajo voluntario, trabajo informal, trabajo a tiempo parcial, etc.; contribuyendo exitosamente a una creciente proletarización de las masas, usando el término en el sentido de que cada vez más personas dependen de la venta de sus capacidades para sobrevivir. ${ }^{24}$

23 Una evaluación de las políticas de inserción laboral de jóvenes en Chile, país pionero en América Latina en este campo, ha verificado que los jóvenes pobres no poseen una expectativa ni están interesados en una inserción laboral estable ni en desarrollar una «carrera», básicamente por los bajos sueldos percibidos y su escasa diferencia con el salario de sus padres; en cambio, se orientan hacia formas esporádicas de inserción al empleo, que satisfagan necesidades de consumo específicas y acotadas en el tiempo (Santiago Consultores, 2001).

24 Como dicen Negri y Hardt (2001): «Las jornadas laborales duran doce, catorce, dieciséis horas, sin fines de semana ni vacaciones; hay trabajo para los hombres, para las mujeres y también para los niños, para los ancianos y también para los discapacitados [...] Cuanto más se desregula el régimen de explotación, tanto más trabajo hay». 


\section{Dos}

La desregulación del régimen de explotación en el capitalismo es paralela a la pérdida de la eficacia de las instituciones que orientaban la reproducción social de las generaciones a través de las antiguas y rígidas instancias de transición a la sociedad adulta, y conlleva formas más flexibles, como las políticas públicas compuestas de pequeños y dispersos proyectos, con efectos semejantes al cercamiento de las antiguas tierras comunales de Inglaterra en el siglo XVIII: la promulgación de la Bill for Inclosure of Commons las expropió para transformarlas en praderas destinadas al ganado, convirtiendo a homogéneas familias de campesinos en heterogéneos trabajadores individuales, despojados de los medios de producción necesarios para reproducir su vida y obligados, por tanto, a venderse a cambio de un salario, legalizando lo que de facto se venía realizando dos siglos antes, mediante el homicidio, el robo y la estafa. Este sometimiento, que requirió de toda la violencia institucionalizada en el naciente Estado capitalista, es parte fundamental del proceso de acumulación.

Marx observa que dicho proceso se divide en dos etapas distintas: durante la primera, que llama «subsunción o supeditación formal del trabajo en el capital», los capitalistas se limitan a convertir los talleres artesanales en empresas capitalistas y a los artesanos en asalariados, pero dejan intacta la organización del trabajo y los medios de producción empleados. Bajo tales condiciones, el capital sólo puede crecer extendiendo la base técnica, esto es, adquiriendo más herramientas y empleando más operarios, durante más horas por jornada y con el mismo salario. El segundo momento, una vez la acumulación capitalista ha llegado a determinados niveles, introduce cambios directos en las condiciones del proceso fabril. Este cambio consistió, en un principio, en la cooperación y la división del trabajo, potenciada por el empleo de maquinaria en gran escala al interior de cada empresa capitalista.

A este momento del proceso, Marx lo llamó «subsunción real del trabajo en el capital», porque el patrón, además de decidir sobre el valor de lo producido, no sólo manda sobre la finalidad de los factores de la producción empleados y la extensión del proceso de trabajo, sino también sobre su intensidad, definiendo la productividad por hora de cada operario con ayuda de la organización científica del trabajo y el uso ampliado de la maquinaria. Así, una vez que el conocimiento científico en sus distintas disciplinas se incorporó a las máquinas y a 
la organización fabril, la fuerza productiva de trabajo social es subsumida como fuerza productiva del capital, y son los medios de producción existentes los que «emplean» a los obreros, y no al contrario.

El pasaje de la subsunción formal a la real constituye un proceso histórico permanente, reiterado periódicamente: cada nueva fase de la acumulación capitalista lo presupone, lo amplía y lo prolonga, cuantitativa y cualitativamente, en extensión y en profundidad. A medida que se completa y profundiza el pasaje de la subsunción formal a la subsunción real, las relaciones capitalistas se extienden a nuevos territorios sociales, expropiando no sólo los servicios de salud y educación, antes a cargo del Estado-empresario, sino también aquellas capacidades que consideramos más universalmente definitorias de lo humano, como las competencias de comunicación y afecto.

De forma parecida a los cercamientos del siglo XVIII, la desinstitucionalización de las relaciones sociales, desde el salario hasta la educación, produce un proletariado arrojado a las más diversas estrategias de sobrevivencia, disponible para los oficios más impensados, generando el crecimiento exponencial del sector terciario, la informalidad y el subempleo, así como el aumento de la criminalidad. ¿Acaso no podemos calificar a los jóvenes como modernos enclousers, y la actividad capitalista tardía e imperialista como un revival expandido de aquella acumulación originaria del capital?: el mismo apoderamiento violento de los medios de producción y reproducción de la vida, la creación de una inmensa fuerza de trabajo dispuesta a venderse por cualquier precio sin la seguridad de saber qué pasará mañana, el incremento de la depredación ecológica a un ritmo cada vez más acelerado. La miseria que sostiene este proceso, que subyace como malestar permanente y rechazo al trabajo, renueva la personería política, como en los albores del capitalismo, a los trabajadores del capitalismo tardío: los obreros precarizados, los desempleados, los campesinos sin tierra, los inmigrantes, las mujeres y los jóvenes. Todos ellos, rebeldes modernos.

\section{REFLEXIONES FINALES}

Si la sociedad tal cual es no contuviera, ocultas, las condiciones materiales de producción y de

circulación para una sociedad sin clases, todas las tentativas de hacerla estallar serían otras tantas quijotadas. KARL MARX 


\section{UNO}

El conflicto generacional es un conflicto de la reproducción social de las generaciones, que en el declive del capitalismo tardío se reviste con la apariencia de una crisis de reconstitución de la hegemonía del mundo adulto depositada en las instituciones que controlan la moratoria social de los jóvenes. Su efecto concreto es la tendencia a la desinstitucionalización de la condición juvenil, equiparable a lo acontecido con otras identidades extraeconómicas, como la abolición de la esclavitud en los albores del capitalismo industrial: la finalidad última de estas operaciones fueron el aumento de la fuerza de trabajo y la disminución de sus costos de reproducción social. Esta desinstitucionalización es compatible con la propensión general del capitalismo a absorber el mayor número de personas en el mercado laboral y reducirlas a unidades intercambiables de trabajo, despojadas de una identidad específica.

Las políticas de juventud tienen por finalidad acompañar este proceso, no resolverlo, promoviendo mecanismos alternativos de inserción sociolaboral, casi siempre en el mercado informal y vinculadas con el desarrollo de habilidades individuales, así como en la promulgación de medidas contra la discriminación generacional que sirven para ocultar su relación estructural con la explotación capitalista. Así, la resolución de la «exclusión» juvenil se reduce a «crear oportunidades» a las que se pueden acceder selectivamente según la pericia individual de los «actores sociales» involucrados y su capacidad de «autogestión», ${ }^{25}$ eufemismo que sirve para denominar la despreciable habilidad de aprovechar, en una forma que combina la necesidad del esquirol con la viveza criolla del marginado, los escasos recursos que se destinan para la reproducción social en beneficio de la explotación de

$25 \mathrm{La}$ «autogestión» es responsable de promover la competencia entre pobres que genera la intervención focalizada de los ministerios y organismos de cooperación internacional, e incorpora una buena dosis de «darwinismo social», en donde la supervivencia viene determinada por la capacidad de crear estrategias de consenso y movilización alrededor de temas políticamente correctos (la reducción de la pobreza, la paz y la convivencia, la democratización de las estructuras políticas, la lucha contra la corrupción, etc.), la destreza para la gestión privada —es decir, oculta y secreta - de los conflictos de poder, y el aprendizaje de los códigos de comunicación legitimados, en forma de conceptos e instrumentos que convalidan la dominación político-económica y las «alternativas» que no cuestionan el orden jurídico burgués. 
la propia clase. En esta lógica competitiva, que debilita las posibilidades de una resistencia colectiva, se induce la microparticipación de grupos sociales diferenciados por edad, género, actividad económica, territorio, etc.; en la periferia del sistema de las decisiones políticas y económicas. En el caso de los jóvenes, se idealizan las virtudes comunitaristas y juventocéntricas que más los alejan de realizar acciones políticas críticas del mundo institucional adulto, en donde se definen, finalmente, los límites de sus aspiraciones de transformación social.

En otras palabras, las políticas de juventud dirigidas contra las discriminaciones generacionales, especialmente las relacionadas con el acceso al mercado laboral y los ingresos, fusionan la indiferencia estructural de la sociedad hacia esta desigualdad, asociada a una diferencia que se «borra» con el tiempo, con un oportunismo sistémico, evidente en los ciclos que periódicamente le quitan o dan relieve como tema de la agenda política. Tal oportunismo se evidencia en las dos formas en que el capitalismo aprovecha las desigualdades puestas en la edad juvenil: i) compartiéndola con otras identidades extraeconómicas, como el género o la identidad racial, intercambiándolas como medio para constituir subclases y hallar distintas cubiertas ideológicas; y ii) como medio para disminuir los costos de la fuerza de trabajo adulta, al instrumentalizar su elevado desempleo como excusa para profundizar selectivamente la desregulación de las relaciones salariales.

Sin embargo, aunque el capitalismo puede hacer un uso ideológico y económico de la opresión generacional, la misma no tiene una situación privilegiada en su estructura de relaciones de producción, lo que de alguna manera pone de manifiesto el lugar un tanto marginal que la problemática tiene en el Estado y entre los distintos «agentes» de la «sociedad civil». De hecho, el capitalismo podría sobrevivir a la erradicación de todas las opresiones generacionales, y también las de género o raciales, mientras que, por definición, no podría sobrevivir a la eliminación de la explotación de clases. Por esto, la necesidad, en tanto instrumentos de gobernabilidad del Estado capitalista, que las políticas de juventud contribuyan a ocultar las realidades estructurales del sistema capitalista y dividan la clase trabajadora, bajo tres orientaciones específicas: i) Sustraer políticamente la juventud perteneciente a sectores históricos de resistencia popular, básicamente funcionarios estatales y empleados urbanos del sector formal de la economía, cuyo peso político ha sido substancialmente disminuido. ii) Fragmentar los intereses y demandas de las clases populares, ante la resignificación por «comunidad de intereses» de aquellos bienes públicos que daban 
cohesión a coaliciones clasistas intergeneracionales (por ejemplo, la educación pública, que agrupó las demandas de maestros, obreros y estudiantes). iii) Pérdida de los mínimos de convivencia generacional, al asociar falazmente los problemas de la incorporación social de los jóvenes como resultado de la resistencia de los intereses corporativistas de los trabajadores adultos y/o al imaginario que asocia al joven con el «vago» e «incapaz».

Lo anterior subraya una consecuencia importante: la lucha contra la discriminación de los jóvenes y su derechos a la participación social, económica y política en términos estrictamente extraeconómicos, es decir, sin cuestionar las relaciones de producción en que tal discriminación, positiva o negativa, cumple una función, no constituyen, en sí, ningún peligro para el capitalismo. De hecho, es una causa que puede triunfar sin grandes oposiciones y cuenta con un moderado interés por parte de los gobiernos y agencias de cooperación; sin embargo, al mismo tiempo, es poco probable que triunfe si se mantiene apartada de la lucha anticapitalista.

\section{Dos}

El movimiento dialéctico que instaura una moratoria como clave determinante de la condición juvenil, y al mismo tiempo la niega, ${ }^{26}$ en virtud de las situaciones materiales en que se concreta, es la clave para definir ontológicamente la actual condición juvenil como una figura esencial de las tensiones de la sociedad actual, entre la posibilidad ilusoria de una libertad individual y la necesidad de una conquista colectiva de la misma.

En la primera, el mercado, como único principio organizador realmente efectivo en la sociedad capitalista, ofrece universalmente la promesa de la libertad, representada en la producción de objetos y discursos fast and light; «la renovación incesante que necesita el mercado capitalista captura el mito de novedad permanente que también impulsa a la juventud», dice Sarlo (1990): la juventud se convierte en

26 Como suele suceder, algunos estudiosos han confundido esta negación con su inexistencia, cuando en realidad nunca antes ha sido más potente la contradicción dialéctica inmanente a la condición juvenil; algo similar opera en aquellos que han expedido, a toda prisa y sin razón, certificados de defunción al trabajo (Offe, Gorz, Rifkin, etc.) o a la historia (Fukuyama). 
la fuente de valores que nutre el imaginario que pone en juego el mercado, que los interpela a través de lo nuevo, lo último, lo rápido, para terminar en una juventud que hace de sí misma un objeto de consumo, cerrando así el círculo.

Contra esto, la desinstitucionalización de la condición juvenil ofrece también la posibilidad de una conquista de la libertad, como oportunidad para desarrollar una moral más autónoma y crítica, enriquecer el itinerario biográfico con experiencias socializadoras menos controladas por los adultos, acceder a la posibilidad inmanente de subvertir el destino suscrito por los orígenes y ocupar un potente campo de transformación social y cultural para la sociedad. Para constituirse en acción revolucionaria, la desinstitucionalización de la condición juvenil necesita develar dos determinantes del conflicto generacional en el capitalismo.

En primer lugar, la determinación de la lucha de clases sobre el conflicto generacional. Reconociendo la existencia de un conflicto generacional que pone en riesgo la reproducción social, los discursos hegemónicos ocultan las condiciones de desigualdad que la sociedad reproduce en este conflicto. Así, se ignora que la edad comporta derechos, privilegios, deberes, formas de actuar, etc.; directamente vinculadas a las dinámicas de reproducción de las clases sociales. Emergen como «realidades» la existencia de jóvenes pobres y ricos identificados por sus atributos generacionales, pero no por su clase, donde hombres y mujeres adquieren una subjetividad histórica.

En segundo lugar, la determinación de las prácticas sociohistóricas de reproducción social de las generaciones sobre la constitución de las identidades juveniles. Se dice que «la juventud es una construcción cultural y administrativa» (Abdala, 2004), significando la trama de instituciones cuyas prácticas ha construido la identidad juvenil. Tales instituciones se ocupan de la reproducción social, que es también la reproducción de las clases sociales y de sus relaciones de dominación política, aplicando un sistema institucional de regulaciones, instancias y prácticas de control y clasificación. En tal sentido si hablamos de una generación juvenil, interpretamos que se trata de personas que comparten, además de una contemporaneidad cronológica, unas mismas condiciones materiales para la producción de sus identidades, aunque con distintos efectos. ${ }^{27}$

27 Aunque la cuestión no puede desarrollarse más ampliamente en este artículo, es importante señalar que la presentación de una «naturaleza 
Por eso es preciso que la participación juvenil promovida por las políticas de juventud se aproveche como táctica para recomponer la coalición intergeneracional dentro de la clase trabajadora y las condiciones que aseguren su reproducción social: no siendo ya el salario el vehículo para imponer la realidad de la unidad del trabajo social en contra de la falaz escisión producción/reproducción del capitalismo, aspecto que hizo posible la realización de los pactos sociotecnoproductivos con la burguesía, las posibilidades de una autovalorización del trabajo por parte del mismo proletariado significa instalar al centro de la lucha de clases el incremento del Gasto Público Social y su control político-económico, como la parte de la reproducción social que el Capital debe pagar.

Esto significa la táctica de implementar un asedio constante y múltiple al Estado burgués para defender y ampliar los derechos conquistados, forzando de esta manera, hasta quebrarlos, los límites del Estado Social de Derecho, es decir, la defensa de la legalidad de la propiedad privada de los medios de producción, y provocar, de esta forma, una crisis política de la vigencia de la ley del valor que sostiene las relaciones de producción capitalistas. En tal sentido, las acciones que propugnan la ampliación de la democracia en el centro de las luchas anticapitalistas tienen una importancia clave (la consigna «todo para todos» es la expresión más sintética y perfecta de la isonomía), mediante la lucha económica a favor de reformas democráticas dentro del capitalismo, destinadas a la acumulación de fuerzas políticas y sociales necesarias para la revolución.

Sin embargo, conviene no hacerse demasiadas ilusiones: cada vez más, cualquier avance del proletariado contra la legalidad burguesa se traduce en una inmediata crisis de su hegemonía política y es respondida al mismo nivel. ${ }^{28} \mathrm{Y}$ esto no puede ser entendido cabalmente si no es en el marco de la actual subsunción del trabajo en el capital, que por la extensión e intensificación de las relaciones de explotación hace

rebelde» como esencia de la juventud sigue estando en la base ideológica de muchos estudios de las culturas juveniles que pasan por alto estas dos determinaciones, disfrazando las desigualdades efectivas como pretenciosas «elecciones» de consumo, asumidas como identificaciones individuales de una subjetividad sin estructura social.

28 «El delito, con sus medios, siempre nuevos, de atacar a la propiedad, reclama también nuevos medios de defensa, desplegando con ello una acción productiva completamente idéntica a la ejercida por las huelgas sobre la invención de las máquinas» (Marx, op. cit.). 
más difícil sostener la ficción de la legalidad de los pactos entre clases, basados en acuerdos de productividad y salario, y trasladados a la política como un consenso impuesto contra la clase trabajadora. De ahí que necesariamente la forma-estado del capitalismo caduco que vivimos no puede ser otra que la del estado fascista-policivo que nunca dejó de ser, aunque sólo ahora desnude su única razón de ser: asegurar la pervivencia del capitalismo mediante la defensa legal de la vigencia de la ley del valor.

En el marco de los esfuerzos de estabilización de la crisis de hegemonía del aparato político-institucional del Estado burgués, el rechazo político al trabajo debe asumir un contravalor fundamental: su legitimidad proletaria es el equivalente de la legalidad burguesa, y entre dos derechos iguales, dejar que decida la fuerza, como decía Marx. Para el caso específico de los jóvenes del proletariado, se trata de dar vuelta, como si fuera un guante, los enfoques integracionistas de las políticas de juventud y volverlos acciones sociopolíticas de afirmación y autonomía: transformar la participación en resistencia; el voluntariado en autovalorización y control del ritmo de trabajo; la selectividad y focalización en solidaridad y unidad de clase; la vinculación como «actor estratégico del desarrollo» en la afirmación radical de los derechos sin vinculación estratégica al desarrollo; las formas de contratación «flexibles» en distribución igualitaria del trabajo entre las generaciones, sin perjuicio de las condiciones de ningún trabajador, en la búsqueda de una reducción del conjunto del tiempo de trabajo necesario de la humanidad. Así, la vivencia de la desesperanza con que cientos de miles de jóvenes acometen, día tras día, una experiencia laboral que ya no los interpela con la misma eficacia que lo hizo con sus padres y abuelos, intuyendo que no obtendrán ni siquiera lo que sus abuelos tuvieron y menos lo que la riqueza creada por el trabajo humano permitiría, debe traducirse en el aumento de la insumisión y la rebeldía.

CAMPINAS (BRASIL), DICIEMBRE 2004 
Políticas de juventud y empleo juvenil

\section{REFERENCIAS BIBLIOGRÁFICAS}

ABAD, M. (2002): «Posibilidades y limitaciones de la participación juvenil para el impacto en la agenda pública: el caso del Consejo Municipal de Juventud en Medellín». Última Década $\mathrm{N}^{\circ} 17$. Viña del Mar: Ediciones CIDPA.

AbDala, E. (2004): Formación y empleabilidad de jóvenes en América Latina. Identidades y formación para el trabajo. Montevideo. OIT/CINTERFOR.

Bourdieu, P. (1990): Sociología y cultura. México: CNCA/Grijalbo.

CONTRERAS, D. (2001): «Política social de juventud: ¿excluir o integrar a qué?». Última Década $\mathrm{N}^{\circ} 14$. Viña del Mar: Ediciones CIDPA.

Grupo DE PRopaganda MARXista (2003): «Necesidad y posibilidad del comunismo». www.nodo50.org/gpm.

HARDT, M. y A. NegRi (2002). Imperio. Buenos Aires: Paidós.

LeVI, G. y J-C. SCHMitT (1996): Historia de los jóvenes (I y II). Madrid: Taurus.

MANDEL, E. (1979): El capitalismo tardío. México: ERA.

MARX, C. (2000). El capital. México: FCE.

Novaes, R. y P. VAnNuchi (2004): Juventude e sociedade. Trabalho, educação, cultura e participação. São Paulo: Instituto Cidadania y Editora Fundação Perseo Abramo.

OLIVEIRA, F. de (2004): «El ornitorrinco». www.rebelion.org.

- (1977): Critica da razon dualista. São Paulo: Ediçoes Cebrap.

Rodríguez, E. (2004): «Construcción de políticas públicas de juventud. Análisis y perspectivas». Bogotá: CINDE, UNICEF, GTZ, Programa Presidencial Colombia Joven.

- (2002): «Insumos para el diseño del libro blanco sobre políticas de juventud en Iberoamérica». Madrid: OIJ.

- (2000): «Consolidando alianzas estratégicas: fortalecimiento institucional y cooperación regional en políticas públicas de juventud en América Latina». Panamá: OIJ.

SAntiago COnSultores (2001): «Evaluación de políticas de inserción laboral de jóvenes». Santiago: INJUV.

SARLO, B. (1990): Escenas de la vida posmoderna. Buenos Aires: Ariel.

Sotelo VAlencia, A. (2004): La reestructuración del mundo del trabajo. Superexplotación y nuevos paradigmas de la organización del trabajo. México: Editorial Itaca.

ToKman, A. (2003): Desemprego juvenil nel cono sul. São Paulo: FES. 